\title{
Effects of switching from olanzapine to aripiprazole on the metabolic profiles of patients with schizophrenia and metabolic syndrome: a double- blind, randomized, open-label study
}

\author{
This article was published in the following Dove Press journal: \\ Neuropsychiatric Disease and Treatment \\ 13 March 2015 \\ Number of times this article has been viewed
}

\author{
Rayees Ahmad Wani \\ Mansoor Ahmad Dar \\ Rajesh Kumar Chandel \\ Yasir Hassan Rather \\ Inaamul Haq \\ Arshad Hussain \\ Altaf Ahmad Malla \\ Department of Psychiatry, \\ Government Medical College, \\ Srinagar, Jammu and Kashmir, India
}

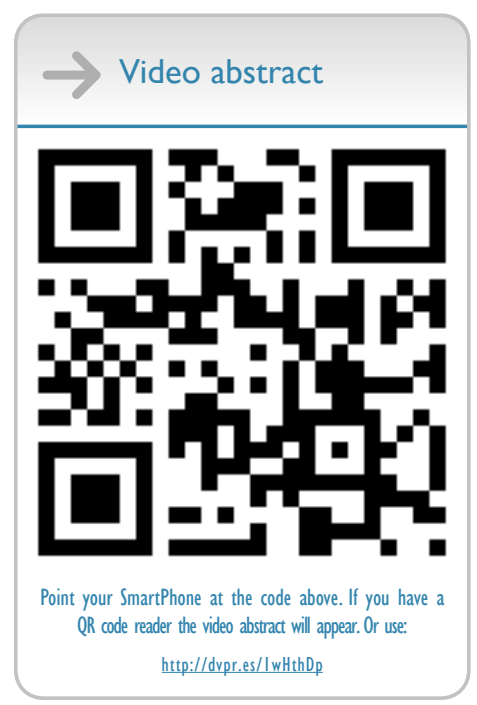

Correspondence: Rayees Ahmad Wani Department of Psychiatry, Government Medical College, Srinagar, Jammu and Kashmir 190003, India Tel +9l 9622427577

Email rayeeswani92@gmail.com
Background: Patients with schizophrenia suffer high rates of metabolic derangements on some antipsychotic medications that predispose them to cardiovascular diseases. Keeping this fact in mind, we planned this open-label study to see the effect on various metabolic parameters after switching stable schizophrenia subjects, who had developed metabolic syndrome on olanzapine, to aripiprazole.

Methods: Sixty-two patients with schizophrenia who were stable on olanzapine and were fulfilling modified National Cholesterol Education Program (NCEP) Adult Treatment Panel III (ATP-III) criteria for the presence of metabolic syndrome were enrolled on the study. Patients were randomly assigned either to switch to aripiprazole or to stay on olanzapine, on a 1:1 basis. Cross-tapering over a period of 1 month was done while switching patients to aripiprazole. Laboratory assessment for metabolic parameters was done at baseline, 8 weeks, and 24 weeks after enrollment; efficacy assessment was done using the Positive and Negative Syndrome Scale (PANSS) at baseline and 24 weeks, the Clinical Global Impressions severity subscale (CGI-S) at baseline, and the Clinical Global Impressions improvement subscale (CGI-I) at 24 weeks. Results: All parameters of metabolic syndrome (waist circumference, blood pressure, triglyceride level, fasting blood glucose, and high-density lipoprotein cholesterol) kept deteriorating in the stay group, compared with a continuous improvement in the switch group over time. At the end of the study, 26 patients (100\%) from the stay group and 15 patients $(42.8 \%)$ from switch group met the modified NCEP ATP-III criteria for presence of metabolic syndrome $(P<0.001)$. There were no statistically significant differences between groups in psychopathology changes as measured by the PANSS total score and CGI-I scores.

Conclusion: Clinically stable patients with schizophrenia who are taking olanzapine and who have evidence of metabolic syndrome can be successfully switched to aripiprazole, with improvement in various parameters of metabolic syndrome and without any significant change in efficacy measures.

Keywords: metabolic syndrome, olanzapine, aripiprazole, schizophrenia, switching

\section{Introduction}

Metabolic syndrome is a complex disorder comprising a set of cardiovascular risk factors, including obesity, dyslipidemia, deranged glucose metabolism, insulin insensitivity, and hypertension. ${ }^{1}$ The clinical significance of metabolic syndrome comes from the fact that it is associated with development of coronary heart disease, cerebrovascular disease, and type 2 diabetes mellitus. Studies show that metabolic syndrome is associated with twofold to threefold increased risk of cardiovascular morbidity. ${ }^{2}$ 
Metabolic syndrome is seen more frequently in persons with schizophrenia than in the general population. ${ }^{3-5}$ While it is possible that genetic factors play a role in the increased risk seen in such patients, it is likely that lifestyle issues such as poor nutrition and reduced exercise habits also play a key role. These metabolic abnormalities are further aggravated by antipsychotic medications. The first-generation antipsychotic medications are effective in treating positive symptoms but are not similarly effective for negative and cognitive symptoms; they are also less protective against relapses in the long-term. ${ }^{6}$ In addition, extrapyramidal symptoms are more commonly seen in patients treated with first-generation antipsychotic medications. ${ }^{7}$ In recent years, atypical antipsychotics, or second-generation antipsychotic medications, have been replacing first-generation antipsychotic medications as firstline treatment for schizophrenia with equal efficacy and fewer extrapyramidal side effects, and have thus ensured a better quality of life for the patient. ${ }^{8-11}$ However, other adverse effects, including weight gain, metabolic syndrome, and cardiovascular side effects, have been found after long-term use of some second-generation antipsychotic medications. ${ }^{12}$

Second-generation antipsychotic medications can cause clinically significant weight gain, leading to insulin resistance and type 2 diabetes mellitus, and are thus a major risk factor for the development of metabolic syndrome. ${ }^{13} \mathrm{~A}$ review of absolute weight gain in various placebo-controlled trials and head-to-head comparisons found that the magnitude of weight gain was not equal among antipsychotic medications. ${ }^{12}$ Maximum weight gain was seen with olanzapine treatment, while it was least with aripiprazole and ziprasidone. Olanzapine was associated with a mean weight gain of $>6 \mathrm{~kg}$ over 1 year, ${ }^{14,15}$ whereas aripiprazole ${ }^{16-19}$ and ziprasidone ${ }^{20-22}$ were associated with a mean weight gain of about $1 \mathrm{~kg}$ over 1 year. Aripiprazole has a unique mechanism of action among second-generation antipsychotic medications: it is a partial agonist at D2 dopamine and 5-HT1A serotonin receptors and an antagonist at 5-HT2A serotonin receptors. ${ }^{23}$ It has the least chance of inducing weight gain and other metabolic side effects ${ }^{24}$ and is safe and effective during both the acute and maintenance phases of schizophrenia. . $92,256^{2}$

Switching antipsychotic medications in the treatment of schizophrenia is a common practice in clinical psychiatry. ${ }^{27}$ Weight gain and metabolic syndrome are the two main reasons for switching antipsychotics. ${ }^{28}$ It has been suggested that the ideal drugs for switching are aripiprazole or ziprasidone, with their low risk for metabolic syndrome. ${ }^{29} \mathrm{We}$ in our study chose aripiprazole because it was the newer option available and we expected it would be of most clinical interest when the study was completed. We hypothesized that switching to aripiprazole would result in an improvement in metabolic measures, compared with staying on olanzapine. We were also interested in determining if switching to aripiprazole would be accompanied by any clinical destabilization. Earlier, Fleischhacker et $\mathrm{a}^{30}$ in their study comparing the efficacy and tolerability of aripiprazole with olanzapine in patients with schizophrenia found that olanzapine had a statistically significant efficacy advantage over aripiprazole, with more reduction in Positive and Negative Syndrome Scale (PANSS) total score. Pae et $\mathrm{al}^{31}$ found that patients switched to aripiprazole, with sudden discontinuation of the previous antipsychotic medication, showed an increase in symptom severity during first week of switching. Moreover, few studies have been done in this field, ${ }^{32,33}$ and none has been from our Kashmir region.

\section{Methods}

\section{Settings and subjects}

The study was carried out at the outpatient unit of a tertiary care psychiatry hospital in North India (Kashmir) from June 2011 to May 2014, after seeking permission from the IEC of the government medical college, Srinagar. Participants were individuals with schizophrenia who had achieved clinical stability with olanzapine and who were assessed as having metabolic syndrome using modified National Cholesterol Education Program (NCEP) Adult Treatment Panel III (ATPIII) criteria. ${ }^{34,35}$ Schizophrenia diagnoses were made using the Diagnostic and Statistical Manual of Mental Disorders, Fourth Text Revision. ${ }^{36}$ The patients were required to be on olanzapine for a minimum of 3 months without any other antipsychotic medication for 1 month prior to enrollment. The patients entered the study in order to improve their metabolic risk profile. Informed consent was obtained from each patient after fully explaining the study procedures.

Patients were randomly assigned either to switch to aripiprazole or to stay on olanzapine, on a 1:1 basis. Individuals assigned to stay on olanzapine remained on their prestudy dosage, with adjustments only as clinically indicated. Olanzapine was used in a dose range of $10-20 \mathrm{mg} /$ day. Patients assigned to switch to aripiprazole began taking aripiprazole $5 \mathrm{mg} /$ day while continuing olanzapine without dose reduction for 1 week. After 1 week, the aripiprazole dosage was increased to $10 \mathrm{mg} /$ day and the dose of olanzapine was reduced $25 \%-50 \%$. After 2 weeks, the aripiprazole dosage could be increased to $15 \mathrm{mg} /$ day while the dose of olanzapine was reduced $50 \%-75 \%$ from the original dosage. 
After 3 weeks, the available range for aripiprazole was 10-20 mg/day, and olanzapine was stopped. After 4 weeks, aripiprazole was used in a dose range of $10-30 \mathrm{mg} /$ day.

Patients were followed on a weekly basis during the first month of the treatment period and every 4 weeks thereafter; laboratory assessment was carried out at baseline, 8 weeks, and 24 weeks after enrollment. PANSS was used at baseline and 24 weeks, while the Clinical Global Impressions severity subscale (CGI-S) was used at baseline and the Clinical Global Impressions improvement subscale (CGI-I) was used at 24 weeks.

The addition of lithium, valproate, statins, or drugs prescribed for weight loss was not allowed during the study. Those who were taking these medications during the prestudy phase were allowed to continue without dose adjustments. All other medications except for nonstudy antipsychotic drugs were allowed.

\section{Assessment}

The waist circumference was measured in a horizontal plane, midway between the inferior margin of the ribs and the superior border of the iliac crest. The measurements were taken thrice and the mean was computed in all cases. Systolic and diastolic blood pressure were measured twice at an interval of 3 minutes in the sitting position after a 15 -minute rest, and the mean was computed. Blood samples $(3 \mathrm{~mL})$ were drawn after 8-12 hours of overnight fasting for the measurement of high-density lipoprotein (HDL) cholesterol, triglycerides, and fasting plasma glucose levels. Plasma glucose was measured using the glucose oxidase-peroxidase method, triglycerides by standard enzymatic procedures, and HDL cholesterol by direct assay method.

Metabolic syndrome was diagnosed using modified NCEP ATP-III criteria for the Asian population. ${ }^{35}$ Diagnosis was made when three or more of the following conditions were met:

1) Waist circumference $>90 \mathrm{~cm}$ for males and $>80 \mathrm{~cm}$ for females;

2) Triglycerides $>150 \mathrm{mg} / \mathrm{dL}$;

3) HDL levels $<40 \mathrm{mg} / \mathrm{dL}$ for males and $<50 \mathrm{mg} / \mathrm{dL}$ for females;

4) Systolic blood pressure $\geq 130 \mathrm{mmHg}$ and/or diastolic blood pressure $\geq 85 \mathrm{mmHg}$;

5) Fasting glucose $\geq 110 \mathrm{mg} / \mathrm{dL}$.

A previous diagnosis of high blood pressure was considered sufficient to fulfill criterion 4 and a previous diagnosis of diabetes mellitus was considered as sufficient to fulfill criterion 5 .
Assessment for any clinical destabilization was done using the PANSS and CGI scales. Efficacy failure was defined by psychiatric hospitalization, a $25 \%$ increase in the total PANSS score, ${ }^{37}$ or ratings of much worse or very much worse on the CGI improvement subscale. ${ }^{38}$

\section{Statistical analysis}

Data were entered into a Microsoft Excel spreadsheet. Continuous variables were summarized as mean and standard deviation. Categorical variables were summarized as percentages. CGI-I and CGI-S were summarized as median and interquartile range. Repeated-measures analysis of variance was used to analyze the difference in the values of a continuous variable over time. Comparisons between stay and switch groups were analyzed using independent samples Student's $t$-test for continuous variables, Chi-square test for categorical variables, Fisher's exact test for categorical variables when the Chi-square test did not meet Cochrane criterion, ${ }^{39}$ and Mann-Whitney test for ordinal variables (CGI-I and CGI-S). The proportion of metabolic syndrome across time was tested using the Cochran $Q$-test. A $P$-value of $<0.05$ was taken as significant.

\section{Results}

Our sample consisted of 62 patients who were randomly assigned to one of two groups, either the stay group $(n=31)$ or the switch group $(n=31)$. The distribution of other (nonstudy) allowed medications among the two groups was statistically insignificant and included lithium $(P>0.999)$, sodium valproate $(P>0.999)$, carbamazipine $(P>0.999)$, lamotrigene $(P>0.999)$, selective serotonin reuptake inhibitors $(P>0.999)$, benzodiazepines $(P=0.554)$, and beta blockers $(P=0.011)$. The progression of the two groups through the study is shown in Figure 1. Ten patients $(32.2 \%)$ from the switch group and five (16.1\%) from the stay group discontinued the treatment before the final assessment at 24 weeks $(P=0.138)$. Table 1 summarizes the sociodemographic characteristics of the participants. Table 2 shows both intergroup and withingroup trends in various metabolic and clinical variables. Last observation carried forward was employed for data imputation. Among the various parameters of metabolic syndrome, waist circumference, blood pressure, triglyceride level, and fasting blood glucose kept increasing in the stay group, while HDL level showed a decreasing trend. In the switch group, waist circumference, blood pressure, triglyceride level, and fasting blood glucose kept decreasing, while HDL level increased with time. 


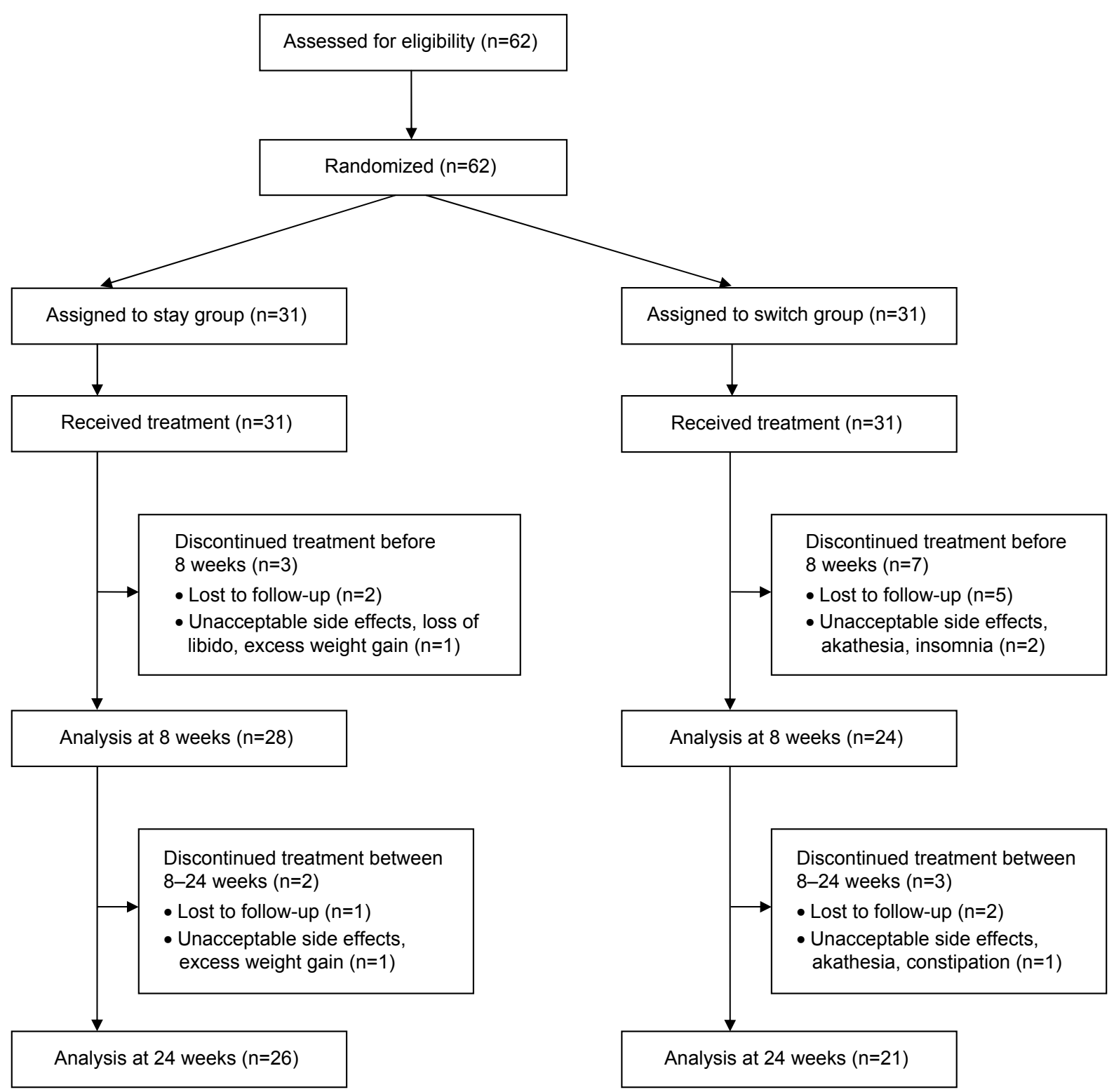

Figure I Patient enrollment and follow up in the study.

Table I Sociodemographic profiles of two groups

\begin{tabular}{|c|c|c|c|}
\hline Characteristics & Stay group $(n=3 I)$ & Switch group $(n=31)$ & $P$-value \\
\hline Age in years, mean (SD) & $29.84(5.24 I)$ & $29.7 I(5.00 I)$ & $0.921^{*}$ \\
\hline Duration of illness in years, mean (SD) & $4.8(3.2)$ & $4.7(3.4)$ & $>0.999 *$ \\
\hline \multicolumn{4}{|l|}{ Sex, n (\%) } \\
\hline Male & $20(64.5)$ & $19(61.3)$ & $0.793 * *$ \\
\hline Female & II (35.5) & $12(38.7)$ & \\
\hline \multicolumn{4}{|l|}{ Marital status, n (\%) } \\
\hline Married & $4(12.9)$ & $5(16.1)$ & $>0.999 * * *$ \\
\hline Divorced & $3(9.7)$ & $3(9.7)$ & \\
\hline Unmarried & $24(77.4)$ & $23(74.2)$ & \\
\hline \multicolumn{4}{|l|}{ Education, n (\%) } \\
\hline Matriculation and above & $12(38.7)$ & $16(51.6)$ & $0.307 * *$ \\
\hline Under matriculation & $19(61.3)$ & $15(48.4)$ & \\
\hline
\end{tabular}

Notes: *Student's t-test. **Pearson Chi-square. ***Fisher's exact test.

Abbreviations: $n$, number; SD, standard deviation. 
Table 2 Metabolic and clinical characteristics of stay group versus switch group

\begin{tabular}{|c|c|c|c|c|c|c|c|c|}
\hline \multirow[t]{2}{*}{ Variables } & \multicolumn{2}{|c|}{ Week 0} & \multicolumn{2}{|c|}{ Week 8} & \multicolumn{2}{|c|}{ Week 24} & \multicolumn{2}{|c|}{$\begin{array}{l}P \text {-value (within } \\
\text { group)** }\end{array}$} \\
\hline & $\begin{array}{l}\text { Stay } \\
\text { group }\end{array}$ & $\begin{array}{l}\text { Switch } \\
\text { group }\end{array}$ & $\begin{array}{l}\text { Stay } \\
\text { group }\end{array}$ & $\begin{array}{l}\text { Switch } \\
\text { group }\end{array}$ & $\begin{array}{l}\text { Stay } \\
\text { group }\end{array}$ & $\begin{array}{l}\text { Switch } \\
\text { group }\end{array}$ & $\begin{array}{l}\text { Stay } \\
\text { group }\end{array}$ & $\begin{array}{l}\text { Switch } \\
\text { group }\end{array}$ \\
\hline \multicolumn{9}{|l|}{ Waist circumference } \\
\hline Mean & 92.71 & 90.26 & 93.71 & 89.32 & 96.58 & 88.23 & $<0.001$ & 0.001 \\
\hline SD & 8.443 & 10.076 & 8.017 & 9.325 & 7.544 & 9.215 & & \\
\hline $\begin{array}{l}P \text {-value } \\
\text { (between groups)* }\end{array}$ & 0.303 & & 0.052 & & $<0.001$ & & - & - \\
\hline \multicolumn{9}{|l|}{ Systolic blood pressure } \\
\hline Mean & 126.39 & $|27.7|$ & 127.06 & 127.23 & 129.32 & $|26.7|$ & 0.003 & 0.288 \\
\hline SD & 10.544 & 11.533 & 11.072 & 11.236 & 10.694 & 10.848 & & \\
\hline $\begin{array}{l}P \text {-value } \\
\text { (between groups)* }\end{array}$ & 0.639 & & 0.955 & & 0.343 & & - & - \\
\hline \multicolumn{9}{|l|}{ Diastolic blood pressure } \\
\hline Mean & 84.32 & 87.81 & 85.23 & 86.77 & 86.77 & 86.77 & 0.003 & 0.470 \\
\hline SD & 9.239 & 12.462 & 8.819 & 11.555 & 7.911 & 10.592 & & \\
\hline $\begin{array}{l}P \text {-value } \\
\text { (between groups)* }\end{array}$ & 0.216 & & 0.556 & & 1.000 & & - & - \\
\hline \multicolumn{9}{|l|}{ Fasting blood sugar } \\
\hline Mean & $|10.8|$ & 118.32 & 114.23 & 114.52 & 118.32 & 112.26 & $<0.001$ & 0.001 \\
\hline SD & 12.677 & 16.388 & 11.724 & 15.423 & 11.828 & 15.044 & & \\
\hline $\begin{array}{l}\text { P-value } \\
\text { (between groups)* }\end{array}$ & 0.048 & & 0.934 & & 0.083 & & - & - \\
\hline \multicolumn{9}{|l|}{ Triglycerides } \\
\hline Mean & 192.19 & 194.32 & 207.26 & 202.74 & 223.61 & 196.35 & $<0.001$ & 0.176 \\
\hline SD & 47.002 & 24.597 & 75.198 & 43.353 & 72.894 & 44.459 & & \\
\hline $\begin{array}{l}P \text {-value } \\
\text { (between groups)* }\end{array}$ & 0.824 & & 0.773 & & 0.082 & & - & - \\
\hline \multicolumn{9}{|l|}{ HDL } \\
\hline Mean & 41.23 & 39.68 & 39.58 & 41.87 & 38.03 & 43.90 & $<0.001$ & $<0.001$ \\
\hline SD & 9.124 & 7.704 & 8.835 & 6.937 & 8.175 & 7.730 & & \\
\hline $\begin{array}{l}P \text {-value } \\
\text { (between groups)* }\end{array}$ & 0.473 & & 0.261 & & 0.005 & & - & - \\
\hline \multicolumn{9}{|l|}{ PANSS } \\
\hline Mean & 68.58 & 69.13 & - & - & 67.61 & 67.74 & 0.001 & 0.002 \\
\hline SD & 4.485 & 5.214 & - & - & 4.318 & 4.719 & & \\
\hline $\begin{array}{l}\text { P-value } \\
\text { (between groups)* }\end{array}$ & 0.659 & & - & & 0.911 & & - & - \\
\hline \multicolumn{9}{|l|}{ CGI-S } \\
\hline Median & 4 & 4 & - & - & - & - & - & - \\
\hline IQR & $3-4$ & $3-4$ & - & - & - & - & & \\
\hline $\begin{array}{l}P \text {-value } \\
\text { (between groups)*** }\end{array}$ & 0.602 & & - & & - & & - & - \\
\hline \multicolumn{9}{|l|}{ CGI-I } \\
\hline Median & - & - & - & - & 4 & 4 & - & - \\
\hline IQR & - & - & - & - & $4-4$ & $3.5-4$ & & \\
\hline $\begin{array}{l}P \text {-value } \\
\text { (between groups)*** }\end{array}$ & - & & - & & 0.375 & & - & - \\
\hline
\end{tabular}

Notes: *Unpaired Student's t-test. **Repeated-measures analysis of variance. ***Mann-Whitney test.

Abbreviations: CGI-I, Clinical Global Impressions improvement subscale; CGI-S, Clinical Global Impressions severity subscale; HDL, high-density lipoprotein cholesterol; IQR, interquartile range; PANSS, Positive and Negative Syndrome Scale; SD, standard deviation.

Table 3 shows the analysis of completers versus noncompleters of the study. Twenty-six patients (100\%) from stay group and 15 patients (42.8\%) from the switch group met the modified NCEP ATP-III criteria for presence of metabolic syndrome $(P<0.001)$ at the end of study.
Two patients from both groups experienced efficacy failure (ie, they were hospitalized). There were no differences between groups in psychopathology changes as measured by the PANSS total score at baseline and 24 weeks $(P=0.911)$ and CGI-I scores at the end of study $(P=0.375)$. 
Table 3 Analysis of completers versus noncompleters of study

\begin{tabular}{|c|c|c|c|}
\hline & Completers & Noncompleters & $P$-value \\
\hline \multicolumn{4}{|l|}{ Group } \\
\hline Stay, $\mathrm{n}$ & 26 & 5 & \multirow[t]{2}{*}{0.138} \\
\hline Switch, $n$ & 21 & 10 & \\
\hline \multicolumn{4}{|l|}{ Residence } \\
\hline Rural, $n$ & 24 & 7 & \multirow[t]{2}{*}{0.767} \\
\hline Urban, $\mathrm{n}$ & 23 & 8 & \\
\hline \multicolumn{4}{|l|}{ Sex } \\
\hline Male, $n$ & 26 & 13 & \multirow[t]{2}{*}{0.029} \\
\hline Female, $\mathrm{n}$ & 21 & 2 & \\
\hline \multicolumn{4}{|l|}{ Marital status } \\
\hline Married, $n$ & 34 & 13 & \multirow[t]{3}{*}{0.683} \\
\hline Unmarried, $\mathrm{n}$ & 8 & I & \\
\hline Previously married, $\mathrm{n}$ & 5 & I & \\
\hline \multicolumn{4}{|l|}{ Education } \\
\hline Under matriculation, $\mathrm{n}$ & 27 & 7 & \multirow[t]{2}{*}{0.465} \\
\hline Matric and above, $\mathrm{n}$ & 20 & 8 & \\
\hline Waist circumference, mean (SD) & $91.00(9.231)$ & $93.00(9.681)$ & 0.473 \\
\hline Systolic blood pressure, mean (SD) & $126.13(11.369)$ & $129.93(9.422)$ & 0.246 \\
\hline Diastolic blood pressure, mean (SD) & $84.34(10.192)$ & $91.47(12.106)$ & 0.028 \\
\hline Fasting blood sugar, mean (SD) & $113.09(13.845)$ & II 9.20 (I7.949) & 0.172 \\
\hline Triglycerides, mean (SD) & $192.04(40.044)$ & $197.07(27.319)$ & 0.653 \\
\hline HDL, mean (SD) & $40.62(8.631)$ & $39.93(7.94 I)$ & 0.787 \\
\hline PANSS, mean (SD) & $69.00(4.482)$ & $68.40(5.950)$ & 0.723 \\
\hline CGI-S, median (interquartile range) & $4(3-5)$ & $4(3-5)$ & 0.761 \\
\hline
\end{tabular}

Abbreviations: CGI-S, Clinical Global Impressions severity subscale; HDL, high-density lipoprotein cholesterol; PANSS, Positive and Negative Syndrome Scale; n, number; $\mathrm{SD}$, standard deviation.

\section{Discussion}

Multiple trials over time have studied the metabolic derangements with second-generation antipsychotic medications. For example, the Clinical Antipsychotic Trials of Intervention Effectiveness (CATIE) Schizophrenia Trial found that, among the antipsychotic medications used, olanzapine was associated with highest risk for weight gain and dyslipidemia, especially elevated triglyceride levels..$^{40-43}$ Various strategies have been adopted to counter these antipsychotic medication-induced metabolic derangements. Switching to antipsychotic medications with lesser metabolic side effects or adopting a lifestyle intervention focused on diet and exercise is the appropriate first step. Addition of statins (3-hydroxy-3-methylglutaryl-coenzyme A reductase inhibitors) to the antipsychotic medication regimen tends to benefit low-density lipoprotein cholesterol and triglycerides rather than HDL or weight, ${ }^{44}$ while adding metformin leads to weight reduction. ${ }^{45,46}$

Switching from olanzapine to aripiprazole in our study was effective in helping many patients improve the results of various parameters of metabolic syndrome, while those who continued on olanzapine experienced further deterioration in these parameters. These findings are in accordance with most of the studies conducted in this field..$^{32,33,47,48}$ The fact that intergroup differences with respect to fasting levels of HDL cholesterol were statistically significant in our study as against the findings of Stroup et $\mathrm{al}^{32}$ could be explained by the fact that we shifted only olanzapine-treated schizophrenia patients to aripiprazole, whereas in the Stroup et al study patients were switched from olanzapine, quetiapine, or risperidone to aripiprazole. Olanzapine causes more metabolic derangements than quetiapine and risperidone, ${ }^{49}$ and this could be the reason that switching produced more beneficial effects in results of fasting levels of HDL cholesterol in our study.

At the end of our study there were no statistically significant differences between groups in psychopathology changes as measured by the PANSS total score $(P=0.911)$ and CGI-I scores $(P=0.375)$ in completers of the study. Fleischhacker et al ${ }^{30}$ found that olanzapine had a statistically significant efficacy advantage over aripiprazole, with more reduction in PANSS total score. McCue et $\mathrm{al}^{50}$ also found that aripiprazole was significantly less able to get patients out of hospital in 3 weeks (the primary outcome measure) compared with olanzapine. In these studies, acute relapsing patients with schizophrenia were shifted to aripiprazole, 
whereas in our study we switched only those patients with schizophrenia who were already stable on olanzapine. It is likely that patients with schizophrenia who are already stable on olanzapine maintain their remission even after switching to aripiprazole; even so, difference exists in acute psychotic episodes, where olanzapine is relatively superior in efficacy to aripiprazole. ${ }^{50}$

Pae et $\mathrm{al}^{31}$ found that patients switched to aripiprazole with sudden discontinuation of the previous antipsychotic medication showed an increase in symptom severity during the first week of switching. In our study, slow crosstitration of antipsychotic medication can explain the reason why there was no significant clinical destabilization in the

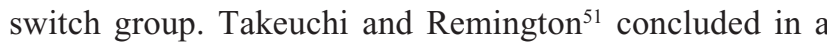
recent systematic review that a small number of patients with schizophrenia or schizoaffective disorder risked an exacerbation of psychotic symptoms if aripiprazole was added to existing antipsychotic treatment. Many of the cases reported involved patients who were quite ill and had been exposed to long-term antipsychotic treatment; it is likely that aripiprazole was added to current treatment in patients with treatment-resistant schizophrenia, but in our study, patients with schizophrenia who were already stable on olanzapine were switched to aripiprazole. As our patients were already stable on olanzapine, this could be a reason for successful switching without much worsening in psychotic symptoms.

The difference in the metabolic derangements between the two groups can be explained by the differential receptor occupancy by aripiprazole and olanzapine. Aripiprazole is a partial agonist at D2 dopamine and 5HT1A serotonin receptors and an antagonist at 5HT2A serotonin receptors, ${ }^{52}$ whereas olanzapine is an antagonist at D2 dopamine, 5HT2A and 5HT2C serotonin, M1 muscarinic, and histamine- 1 receptors. ${ }^{53}$ Histamine- 1 and 5HT2C receptor antagonism closely correlates with the weight-gaining potential of some antipsychotics like olanzapine ${ }^{54,55}$ and may interfere with leptin-mediated appetite suppression..$^{55,56}$ Adiposity alone does not explain the diabetogenic potential of some atypical antipsychotic medications. ${ }^{57}$ Significant insulin resistance, even with a single dose of olanzapine, has also been documented in nonobese individuals receiving olanzapine versus those receiving risperidone. ${ }^{58,59}$ Blocking M3 (type 3) muscarinic and 5HT1A receptors may be a factor in diminished pancreatic beta-cell responsiveness, and blocking 5HT2A receptor may suppress glucose uptake in skeletal muscle. ${ }^{53}$
Treatment with olanzapine in patients with schizophrenia offers the advantage of effectiveness for both positive and negative symptoms, with the fewest extrapyramidal side effects. ${ }^{8-11}$ However, because of growing evidence of olanzapine-induced metabolic derangements, as is evident from our study also, a prescribing choice must be based on an assessment of each drug's efficacy as well as its potential to cause metabolic side effects. Because schizophrenia is a chronic illness that requires antipsychotic treatment for a prolonged period, an antipsychotic agent with fewer metabolic side effects, such as aripiprazole, can be used for maintenance, to prevent psychotic relapse and long-term deterioration. As is evident from our study, the dropout rate was higher in the switch group than in the stay group $(P=0.138)$, which can be an impediment in stabilized schizophrenia patients while switching them to other antipsychotic medications and is something that clinicians will want to address. This problem can partially be addressed by slow cross-titration of drugs and close follow-up of such patients. Monitoring blood levels of aripiprazole is a meaningful option, because it seems to have a therapeutic window at $150-210 \mathrm{ng} / \mathrm{mL} .^{60}$ Levels beyond $210 \mathrm{ng} / \mathrm{dL}$ will lead to more side effects, and levels below $150 \mathrm{ng} / \mathrm{dL}$ will show subtherapeutic response and thus lead to more dropouts.

\section{Conclusion}

Clinically stable patients with schizophrenia on olanzapine who have evidence of metabolic syndrome can be successfully switched to aripiprazole, with improvement in various parameters of metabolic syndrome and without any significant change in efficacy measures. Switching is an option if careful cross-titration and close monitoring is possible. Careful clinical monitoring after a switch to aripiprazole might have been the reason that those who switched did not experience a higher rate of efficacy failures, compared with those who stayed on olanzapine.

\section{Disclosure}

There are no financial or other relationships that might lead to a conflict of interest. The authors report no other conflicts of interest in this work.

\section{References}

1. Reaven GM. Syndrome X: 6 years later. J Int Med Suppl. 1994;736: 13-22.

2. Lakka HM, Laaksonen DE, Lakka TA, et al. The metabolic syndrome and total and cardiovascular disease mortality in middle-aged men. JAMA. 2002;288(21):2709-2716. 
3. Patel JK, Buckley PF, Woolson S, et al; CAFE Investigators. Metabolic profiles of second-generation antipsychotics in early psychosis: findings from the CAFE study. Schizophr Res. 2009;111(1-3):9-16.

4. McEvoy JP, Meyer JM, Goff DC, et al. Prevalence of the metabolic syndrome in patients with schizophrenia: baseline results from the Clinical Antipsychotic Trials of Intervention Effectiveness (CATIE) schizophrenia trial and comparison with national estimates from NHANES III. Schizophr Res. 2005;80(1):19-32.

5. Meyer JM, Nasrallah HA, McEvoy JP, et al. The Clinical Antipsychotic Trials Of Intervention Effectiveness (CATIE) Schizophrenia Trial: clinical comparison of subgroups with and without the metabolic syndrome. Schizophr Res. 2005;80(1):9-18.

6. Altamura AC, Buoli M, Mauri MC. Haloperidol versus secondgeneration antipsychotics in the long-term treatment of schizophrenia: a 4-year follow-up naturalistic study. J Clin Psychopharmacol. 2011;31(5):661-663.

7. Jibson MD, Tandon R. New atypical antipsychotic medications. J Psychiatr Res. 1998;32(3-4):215-228.

8. Davis JM, Chen N. Clinical profile of an atypical antipsychotic: risperidone. Schizophr Bull. 2002;28(1):43-61.

9. Davis JM, Chen N. The effects of olanzapine on the 5 dimensions of schizophrenia derived by factor analysis: combined results of the North American and international trials. J Clin Psychiatry. 2001; 62(10):757-771

10. Karow A, Naber D. Subjective well-being and quality of life under atypical antipsychotic treatment. Psychopharmacology (Berl). 2002; 162(1):3-10.

11. Chong MY, Tan CH, Fujii S, et al. Antipsychotic drug prescription for schizophrenia in East Asia: rationale for change. Psychiatry Clin Neurosci. 2004;58(1):61-67.

12. Newcomer JW. Second-generation (atypical) antipsychotics and metabolic effects: a comprehensive literature review. CNS Drugs. 2005; 19 Suppl 1:1-93.

13. Pi-Sunyer FX. Medical hazards of obesity. Ann Intern Med. 1993; 119(7 Pt 2):655-660.

14. Nemeroff CB. Dosing the antipsychotic medication olanzapine. J Clin Psychiatry. 1997;58 Suppl 10:45-49.

15. Kinon BJ. The routine use of atypical antipsychotic agents: maintenance treatment. J Clin Psychiatry. 1998;59 Suppl 19:18-22.

16. Marder SR, McQuade RD, Stock E, et al. Aripiprazole in the treatment of schizophrenia: safety and tolerability in short-term, placebocontrolled trials. Schizophr Res. 2003;61(2-3):123-136.

17. Kasper S, Lerman MN, McQuade RD, et al. Efficacy and safety of aripiprazole vs haloperidol for long-term maintenance treatment following acute relapse of schizophrenia. Int $J$ Neuropsychopharmacol. 2003;6(4):325-337.

18. Pigott TA, Carson WH, Saha AR, Torbeyns AF, Stock EG, Ingenito GG; Aripiprazole Study Group. Aripiprazole for the prevention of relapse in stabilized patients with chronic schizophrenia: a placebo-controlled 26-week study. J Clin Psychiatry. 2003;64(9):1048-1056.

19. McQuade RD, Jody D, Kujawa M, Carson WH, Iwamoto T. Long-term weight effects of aripiprazole versus olanzapine. American Psychiatric Association (APA) 156th Annual Meeting; 2003 May 17-22; San Francisco, CA.

20. Allison DB, Mentore JL, Heo M, et al. Antipsychotic-induced weight gain: a comprehensive research synthesis. Am J Psychiatry. 1999; 156(11):1686-1696.

21. Daniel DG, Zimbroff DL, Potkin SG, Reeves KR, Harrigan EP, Lakshminarayanan M. Ziprasidone $80 \mathrm{mg} /$ day and $160 \mathrm{mg} /$ day in the acute exacerbation of schizophrenia and schizoaffective disorder: a 6-week placebo-controlled trial. Ziprasidone Study Group. Neuropsychopharmacology. 1999;20(5):491-505.

22. Hirsch SR, Kissling W, Bäuml J, Power A, O'Connor R. A 28-week comparison of ziprasidone and haloperidol in outpatients with stable schizophrenia. J Clin Psychiatry. 2002;63(6):516-523.

23. Swainston Harrison T, Perry CM. Aripiprazole: a review of its use in schizophrenia and schizoaffective disorder. Drugs. 2004;64(15): 1715-1736.
24. Newcomer JW. Metabolic considerations in the use of antipsychotic medications: a review of recent evidence. J Clin Psychiatry. 2007; 68 Suppl 1:20-27.

25. Potkin SG, Saha AR, Kujawa MJ, et al. Aripiprazole, an antipsychotic with a novel mechanism of action, and risperidone vs placebo in patients with schizophrenia and schizoaffective disorder. Arch Gen Psychiatry. 2003;60(7):681-690

26. Kane JM, Carson WH, Saha AR, et al. Efficacy and safety of aripiprazole and haloperidol versus placebo in patients with schizophrenia and schizoaffective disorder. J Clin Psychiatry. 2002;63(9):763-771.

27. Burns T, Chabannes JP, Demyttenaere K. Switching antipsychotic medications: general recommendations and switching to amisulpride. Curr Med Res Opin. 2002;18(4):201-208.

28. Weiden PJ, Miller AL, Lambert TJ, Buckley PF. The art and science of switching antipsychotic medications, part 2. J Clin Psychiatry. 2007;68(1):e02.

29. Weiden PJ, Buckley PF. Reducing the burden of side effects during long-term antipsychotic therapy: the role of "switching" medications. J Clin Psychiatry. 2007;68 Suppl 6:14-23.

30. Fleischhacker WW, McQuade RD, Marcus RN, Archibald D, Swanink R, Carson WH. A double-blind, randomized comparative study of aripiprazole and olanzapine in patients with schizophrenia. Biol Psychiatry. 2009;65(6):510-517.

31. Pae CU, Serretti A, Chiesa A, et al. Immediate versus gradual suspension of previous treatments during switch to aripiprazole: results of a randomized, open label study. Eur Neuropsychopharmacol. 2009;19(8):562-570.

32. Stroup TS, McEvoy JP, Ring KD, et al; Schizophrenia Trials Network. A randomized trial examining the effectiveness of switching from olanzapine, quetiapine, or risperidone to aripiprazole to reduce metabolic risk: comparison of antipsychotics for metabolic problems (CAMP). Am J Psychiatry. 2011;168(9):947-956.

33. Newcomer JW, Campos JA, Marcus RN, et al. A multicenter, randomized, double-blind study of the effects of aripiprazole in overweight subjects with schizophrenia or schizoaffective disorder switched from olanzapine. J Clin Psychiatry. 2008;69(7):1046-1056.

34. Expert Panel on Detection, Evaluation, and Treatment of High Blood Cholesterol in Adults. Executive summary of the third report of the National Cholesterol Education Program (NCEP) Expert Panel on Detection, Evaluation, and Treatment of High Blood Cholesterol in Adults (Adult Treatment Panel III). JAMA. 2001;285(19):2486-2497.

35. Heng D, Ma S, Lee JJ, et al. Modification of the NCEP ATP III definitions of the metabolic syndrome for use in Asians identifies individuals at risk of ischemic heart disease. Atherosclerosis. 2006;186(2):367-373.

36. American Psychiatric Association. Diagnostic and Statistical Manual and Mental Disorders, 4th ed, text rev, Washington DC, American psychiatric association 2000.

37. Kay SR, Fiszbein A, Opler LA. The Positive and Negative Syndrome Scale (PANSS) for schizophrenia. Schizophr Bull. 1987;13(2): 261-276.

38. Guy W. ECDEU Assessment Manual for Psychopharmacology-Revised (DHEW Publ No ADM 76-338). Rockville, MD: US Department of Health, Education, and Welfare, Public Health Service, Alcohol, Drug Abuse, and Mental Health Administration, NIMH Psychopharmacology Research Branch, Division of Extramural Research Programs; 1976:218-222.

39. Armitage P, Berry G, Matthews JNS. Analysing means and proportions. In: Armitage P, Berry G, Matthews JNS. Statistical Methods in Medical Research. 4th ed. Malden, MA: Blackwell Science Ltd; 2002:83-146.

40. Lieberman JA, Stroup TS, McEvoy JP, et al; Clinical Antipsychotic Trials of Intervention Effectiveness (CATIE) Investigators. Effectiveness of antipsychotic drugs in patients with chronic schizophrenia. N Engl J Med. 2005;353(12):1209-1223.

41. Meyer JM, Davis VG, Goff DC, et al. Change in metabolic syndrome parameters with antipsychotic treatment in the CATIE Schizophrenia Trial: prospective data from phase 1. Schizophr Res. 2008;101(1-3):273-286. 
42. Nasrallah HA. Metabolic findings from the CATIE trial and their relation to tolerability. CNS Spectr. 2006;11(7 Suppl 7):32-39.

43. Stroup TS, Lieberman JA, McEvoy JP, et al; CATIE Investigators. Effectiveness of olanzapine, quetiapine, risperidone, and ziprasidone in patients with chronic schizophrenia following discontinuation of a previous atypical antipsychotic. Am J Psychiatry. 2006; 163(4):611-622.

44. De Hert M, Kalnicka D, van Winkel R, Wampers M, Hanssens L, Van Eyck D, et al. Treatment with rosuvastatin for severe dyslipidemia in patients with schizophrenia and schizoaffective disorder. $J$ Clin Psychiatry. 2006;67(12):1889-1896.

45. Wu RR, Zhao JP, Jin H, et al. Lifestyle intervention and metformin for treatment of antipsychotic-induced weight gain: a randomized controlled trial. JAMA. 2008;299(2):185-193.

46. Wu RR, Zhao JP, Guo XF, et al. Metformin addition attenuates olanzapine-induced weight gain in drug-naive first-episode schizophrenia patients: a double-blind, placebo-controlled study. Am J Psychiatry. 2008;165(3):352-358.

47. McQuade RD, Stock E, Marcus R, et al. A comparison of weight change during treatment with olanzapine or aripiprazole: results from a randomized, double-blind study. J Clin Psychiatry. 2004;65 Suppl 18: $47-56$.

48. Chrzanowski WK, Marcus RN, Torbeyns A, Nyilas M, McQuade RD. Effectiveness of long-term aripiprazole therapy in patients with acutely relapsing or chronic, stable schizophrenia: a 52-week, openlabel comparison with olanzapine. Psychopharmacology (Berl). 2006;189(2):259-266.

49. Hasnain M, Vieweg WV, Fredrickson SK, Beatty-Brooks M, Fernandez A, Pandurangi AK. Clinical monitoring and management of the metabolic syndrome in patients receiving atypical antipsychotic medications. Prim Care Diabetes. 2009;3(1):5-15.

50. McCue RE, Waheed R, Urcuyo L, et al. Comparative effectiveness of second-generation antipsychotics and haloperidol in acute schizophrenia. Br J Psychiatry. 2006;189:433-440.
51. Takeuchi H, Remington G. A systematic review of reported cases involving psychotic symptoms worsened by aripiprazole in schizophrenia or schizoaffective disorder. Psychopharmacology (Berl). 2013;228(2):175-185.

52. American Diabetes Association, American Psychiatric Association, American Association of Clinical Endocrinologists, North American Association for the Study of Obesity. Consensus development conference on antipsychotic drugs and obesity and diabetes; pp. Diabetes Care. 2004;27(2):596-601.

53. Citrome L. Olanzapine: interpreting the label change. Int J Clin Pract. 2007;61(12):1960-1962.

54. Nasrallah HA. Atypical antipsychotic-induced metabolic side effects: insights from receptor-binding profiles. Mol Psychiatry. 2008;13(1): $27-35$.

55. Reynolds GP, Hill MJ, Kirk SL. The 5-HT2C receptor and antipsychoticinduced weight gain - mechanisms and genetics. J Psychopharmacol. 2006;20(4 Suppl):15-18.

56. Matsui-Sakata A, Ohtani H, Sawada Y. Receptor occupancy-based analysis of the contributions of various receptors to antipsychoticsinduced weight gain and diabetes mellitus. Drug Metab Pharmacokinet. 2005;20(5):368-378.

57. Newcomer JW, Haupt DW. The metabolic effects of antipsychotic medications. Can J Psychiatry. 2006;51(8):480-491.

58. Henderson DC, Cagliero E, Copeland PM, et al. Glucose metabolism in patients with schizophrenia treated with atypical antipsychotic agents: a frequently sampled intravenous glucose tolerance test and minimal model analysis. Arch Gen Psychiatry. 2005;62(1):19-28.

59. Hahn MK, Wolever TM, Arenovich T, et al. Acute effects of singledose olanzapine on metabolic, endocrine, and inflammatory markers in healthy controls. J Clin Psychopharmacol. 2013;33(6):740-746.

60. Sparshatt A, Taylor D, Patel MX, Kapur S. A systematic review of aripiprazole - dose, plasma concentration, receptor occupancy, and response: implications for therapeutic drug monitoring. J Clin Psychiatry. 2010;71(11):1447-1456.
Neuropsychiatric Disease and Treatment

\section{Publish your work in this journal}

Neuropsychiatric Disease and Treatment is an international, peerreviewed journal of clinical therapeutics and pharmacology focusing on concise rapid reporting of clinical or pre-clinical studies on a range of neuropsychiatric and neurological disorders. This journal is indexed on PubMed Central, the 'PsycINFO' database and CAS,

\section{Dovepress}

and is the official journal of The International Neuropsychiatric Association (INA). The manuscript management system is completely online and includes a very quick and fair peer-review system, which is all easy to use. Visit http://www.dovepress.com/testimonials.php to read real quotes from published authors. 